\title{
Técnica dormido-despierto-dormido en paciente anciano, uso Ima y tiva, para resección tumoral cerebral
}

\author{
Díaz NB. ${ }^{1}$, Acosta MA. ${ }^{1}$, Carabajal Rodríguez JM. ${ }^{1}$, Sandez FN. ${ }^{1,2}$, Bolzón I. ${ }^{1}$ \\ 1 Hospital Regional Ramón Carrillo, Santiago del Estero, Argentina. \\ 2 Sanatorio Alberdi, Santiago del Estero, Argentina.
}

Introducción: La neurocirugía con paciente despierto es un método útil en lesiones próximas a áreas elocuentes cerebrales para optimizar la resección de tumores y preservar la función neurológica.

Descripción del caso: Paciente femenina de 79 años, $65 \mathrm{~kg}$, con disartria y ataxia en mano derecha, evoluciona a hemiparesia severa derecha, con evidencia de lesión expansiva quística subcortical temporoparietal izquierda en íntima relación con el área motora y del lenguaje, afasia mixta a predominio derecho. Antecedente de cáncer de mama y metástasis pulmonar (resuelto), anticoagulada, con arritmias cardiacas, hipotiroidismo. Se realiza resección de tumor, bajo técnica dormido-despierto-dormido, con uso de potenciales evocados somatosensitivos y motores. Inicio: dosis de carga de dexmedetomidina de $1 \mathrm{mcg} / \mathrm{kg}$, en 20 minutos, infusión de remifentanilo $0,03 \mathrm{mcg} / \mathrm{kg} / \mathrm{min} 5$ minutos antes de realizar la inducción con propofol en bolo lento de $60 \mathrm{mg}$, para la colocación de la máscara laríngea Aura Gain $\mathrm{N}^{\mathrm{o}} 4$ sin complicaciones. Infiltración del colgajo con bupivacaína isobárica 0,25\%. Mantenimiento: ARM, infusión de propofol a $6 \mathrm{mg} / \mathrm{kg} / \mathrm{h}$ los primeros 10 minutos luego a $4 \mathrm{mg} / \mathrm{kg} / \mathrm{h}$, remifentanilo a $0,3 \mathrm{mgc} / \mathrm{kg} / \mathrm{min}$ y dexmedetomidina $0,03 \mathrm{mcg} / \mathrm{kg} / \mathrm{h}$. A los 40 minutos de iniciada la cirugía se procede a suspender las infusiones de propofol y remifentanilo y se continúa con infusión de dexmedetomidina a $0,03 \mathrm{mcg} / \mathrm{kg} / \mathrm{h}$. Aproximadamente a los 15 minutos la paciente despierta, se retira la máscara laríngea, se coloca cánula nasal, se realiza evaluación del habla y respuesta a órdenes sin inconvenientes, se le pide a la paciente que abra la boca, se coloca LMA con buena tolerancia, inmediatamente se realiza bolo de propofol $60 \mathrm{mg}$. Continuamos con propofol a $4 \mathrm{mg} / \mathrm{kg} / \mathrm{h}$, remifentanilo a $0,3 \mathrm{mcg} /$ $\mathrm{kg} / \mathrm{min}$, se mantiene la dosis de dexmedetomidina a $0,03 \mathrm{mcg} / \mathrm{kg} / \mathrm{h}$. Tiempo quirúrgico $180 \mathrm{~min}$. Paciente se recupera con Aldrete $10 / 10$ y se traslada a terapia intensiva.

Información adicional: Colocación de línea arterial, sonda Foley y dos vías periféricas 20 G y una 16 G. Hemodinámicamente estable durante toda la cirugía. Posición de cirugía: decúbito dorsal con rotación de la cabeza hacia la derecha. Uso de bomba jeringa.

Discusión: Los adultos mayores presentan mayor sensibilidad a los anestésicos intravenosos a nivel del SNC y tienen respuestas hemodinámicas incrementadas. El uso de máscara laríngea está aceptado para este tipo de cirugía. El paciente adulto mayor debe ser previamente evaluado cognitivamente para verificar si será colaborador y disminuir su ansiedad dándole las herramientas e información necesarias para la compresión del procedimiento.

https://doi.org/10.25237/congresoclasa2019.90 